\title{
How Far can Aids Improve the Socio-Economic Well-Being of Flood Victims in Kelantan?
}

\author{
Rohani Mohd \\ Faculty Business and Management, Universiti Teknologi MARA, Selangor, Malaysia \\ Email: Rohani191@salam.edu.my \\ Nordin Abu Bakar \\ Faculty Computer Science, Universiti Teknologi MARA, Selangor, Malaysia \\ Email: drnordin@salam.edu.my \\ Salwana Hassan \\ Faculty Business and Management, Universiti Teknologi MARA, Selangor, Malaysia \\ Email:salwana@salam.uitm.edu.my \\ Afifuddin Husairi \\ Rasch Measurement Malaysia Chapter (myRasch), Selangor, Malaysia \\ Email: afifuddinhusairigmail.com
}

\section{Doi:10.5901/mjss.2016.v7n4p}

\section{Abstract}

\begin{abstract}
The life of an individual or a community involved in a disaster must be restored socially as well as economically the same level as before. However, the devastating impact of the disaster such as the great flood of 2014 has made it impossible to regain exactly the same socio economic well-being. In Kelantan particularly, many aids have been handed out by many organizations both public and private agencies in order to help the community gain its normal life. Thus, the purpose of this study was to evaluate the effectiveness of the aids provided. The changes in their satisfaction for the way they live would reflect the effectiveness of the aids provided. A survey has been implemented in the selected villages; namely, Kg Pahi and Kg Tualang in Kuala Krai. 150 respondents were interviewed. The Rasch analysis was employed to analyze the level of effectiveness. The findings showed that all aids were moderately effective as the victims' quality of life has moderately improved. Some aids were needed more than the others. Therefore, the Malaysian government with the collaborative effort of the NGOs need to provide aids that could give long term effect. For that reason, an unbrella business concept which requires cooperative effort of each family in the village to manage various small businesses can be introduced.
\end{abstract}

Keywords: socio economic, quality of life, Rasch, flood, effectiveness

\section{Introduction}

In any disaster, the victims were always provided with aids that were believed to improve their socio economic well-being at least temporarily. These aids were provided by a government and nonprofit organizations in many forms. The aids were mostly in the form of moral support, financial support, temporary shelter, food and basic necessities which were temporary in nature. Researches in the past were generally on the recovery coping strategies of disaster victims (Skoufias, 2003; Reganit 2005). Very few studies conducted on the effectiveness of the aids provided. The most common recovery coping strategies found to be adopted by the victims were livelihood strategies which include the construction of houses with second floor to escape from flood, purchasing of food stock, saving money, and looking for alternative jobs. Even though the aids were temporary, the impacts of these aids on the quality of life of the victims would be significant even though may be little. However, the impact of the aids provided was seldom researched. If this is studied, at least, the government could identify which aids to be given more and how much more to be provided to improve the quality of life of the victims significantly so that the socio-economic well-being of the victims improved. There were very few research conducted on either the effectiveness of recovery plan or the effectiveness of the aids provided by those involved in supporting the disaster victims. Therefore, the purpose of this research paper is to investigate the 
effectiveness of the aids provided by the Malaysian government and nonprofit organizations to the flood victims in Kuala Krai, Kelantan, Malaysia.

\section{Literature Review}

The quality of life takes into consideration a few dimensions that determine the well-being of an individual and everyone around him meets a certain standard of living. Generally this standard retains the comfortable and sustainable socio economic activities that support one's daily life. Studies on similar context have been done by Twigger-Ross(2006), Thrush et al (2005), and Tapsell et al.(2005). Empirical understanding on the devastation of the flood would portray a more accurate picture of the processes and that people go through in recovering from the flood disaster. The existing post flood studies by Tapsell et al (2003) and Werrity et al (2007) have mentioned the importance to extend further study on the interaction between social, economic and health impacts with overall quality of life. Brown and Damery (2002) suggested an understanding from the people affected by the flood on the engineering and technological solution is important for effective flood management.

In Malaysia, Johari and Marzuki (2013) have reported their study on flood victim's quality of life and focused on the social and emotional impacts of the flood. The traumatic experience and persistent worries among them led to depression and negative social behaviours. Felce and Perry (1995) defined quality of life as an overall general well-being that consists of objective descriptors and subjective evaluations of physical, material, social and emotional well-being together with the extent of personal development and purposeful activity, all weighted by a personal set of values. This is further enhanced by Cummin (2003) that quality of life is both objective and subjective which is the composite of seven domains: material well-being, health, productivity, intimacy, safety, community and emotional well-being.

Diener (2009) on the other hand defined well being, the situation when 'life is good' as the general evaluation of one's quality of life which includes interest, prudential value, welfare, happiness and utility and it is the composition of a cognitive appraisal of his life (life satisfaction) with the experience of pleasant emotions and relatively low levels of negative moods. Therefore well-being is a form of happiness used as a global assessment of a person's quality of life.

Obtaining a basic quality of life (QoL) is having the minimum standard of basic necessities to ensure a comfortable living for an average family which will improve human capabilities in terms of health, education, skills and equitable access to opportunities in political, culture and social (Hasanuz Zaman ,1991). With various definitions provided by previous researches on the term of 'quality of life', there were some common aspects: good life, satisfaction in social, economic and health. Therefore, for this study, the focus was given to the satisfaction of flood victims on their social, economic and health after the aids were provided. Pictures indicating the physical improvement could only tell the external change which is objective in nature but may not reflect their emotional well-being and happiness. Since the quality of life is measured by the victims' perception on their satisfaction for what they feel about their life before and after the disaster, therefore, the effectiveness of the aids provided to them would be measured by the size of the gap that exist between their satisfaction for the aids provided before and after the flood. The satisfaction for the aids would be determined by their perception on the level of quality of life the felt before and after the flood.

\section{Research Methods}

The socio economic well-being of flood victims depend so much on the level of their quality of life (QoL). According to Annoni and Biolowolska (2012), QoL is a multi-dimensional concept comprising objective measures, describing economic and social opportunities, and people's perceptions of these resources, which we understand as subjective measures of objective aspects. Therefore our measure of QoL envisages the measurement of several dimensions. Each dimension is also multidimensional and consists of different sub-dimensions, that we call components. Both objective and subjective indicators populate each QoL dimension. Objective indicators are intended as 'drivers' of QoL and subjective measures are used to gauge the actual effectiveness of the drivers, in other term to assess how good they are perceived. Objective and subjective indicators are separated into different components within each dimension. This paper presents the first results and focuses only a dimension of QoL, that is people perception's of economic and social opportunity.

For this research, data was analyzed using Rasch analysis because it is the best tool that can effectively measure the length of gap between items before and after, with its special scale called "logit" unit. The measure was produced in the form of a ruler that could display the level of satisfaction of the victims on aids provided before and after. The aids measured by the study were basic necessities, kitchen appliances, temporary house, permanent house, school kits, and financial aids (economic reliefs). The respondents were asked to rate their satisfaction level for all 10 items related to quality of life, before and after the aids were provide. The answers from the questions interviewed were coded and 
transferred into excel so that rasch analysis can be conducted as to see pattern of answers and an index of quality of life (in logit unit) of victims can be derived. Before the analyses were conducted, the data must be tested for its goodness fit to the model of Rasch. This involved determining the reliability and validity of the items, and the unidimensionality of the items measured. In order to identify the effectiveness of the aids, the racking analysis was conducted which was illustrated in a ruler called effective ruler of rasch. To achieve this, the respondents had to recall what they experienced (their quality of life in terms of their health condition, their house condition, the clothing, the community security and other basic needs) before the aids and what they were experiencing after the provision of the aids.

For this research, samples were victims from Kuala Krai and Gua Musang. However, this paper only reported the results gathered from Kuala Krai, Kelantan.

\section{Results And Discussions}

There were two analyses involved: first analysis was determining the goodness fit of the data to the model, the second part of the analyses was answering the research objective.

\subsection{The First Analysis}

Table 1 shows that the data for this research was good. This is indicated by the reliability of both persons and items which were above .7. Person reliability of .83 indicating there were sufficient items to measure the difficulty level of the items, and the item reliability of .97 indicating that there were sufficient persons to measure people's ability (quality of life$\mathrm{QOL}$ ) level. The cronbach alpha of .99 indicating good internal item consistency. The person mean of 0.35 logit indicating that in general the victims' quality of life was moderately low as it was just above 0.0 logit of item mean. The low standard error of .02 reflecting the precision of the data compared to the actual. The highest level of the victim quality of life was just 1.29 logits while the lowest was -.32 logit.

Table 1: the summary statistics of the data (reported: 150 Person 42 Item 56 Cats Winsteps 3.72.3)

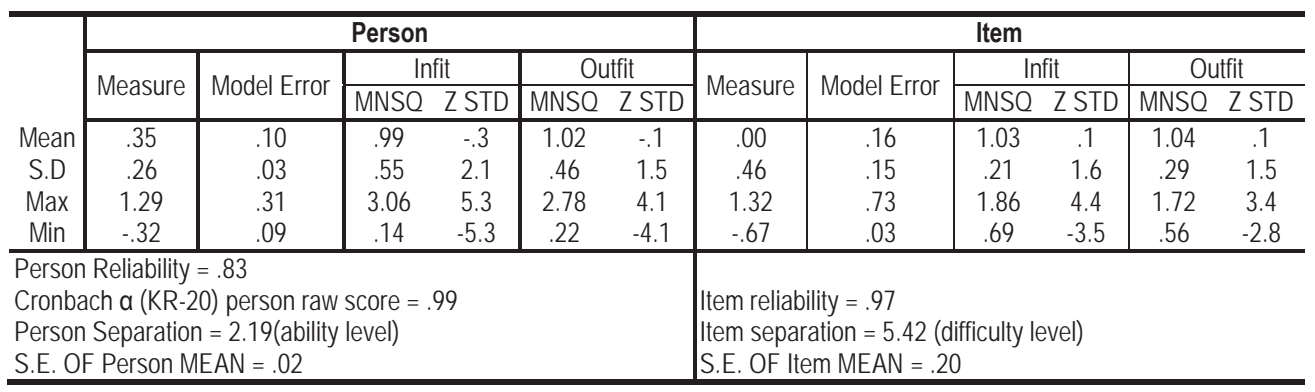

Unidimensionality is crucial to ensure the instrument measuring the specific objectivity. For this test, Rasch analysis applies the principal component analysis (PCA) of the residuals; i.e. how much variance is the instrument in measuring what is supposedly measured. The raw variance explained by measure was $40 \%$. It met the unidimensionality requirement of $40 \%$ (Conrad et al., 2011).

Nevertheless, the unexplained variance in the first contrast of $9 \%$ as tabulated in Table 3 exhibited that the instrument was considered to be very good (Bond \& Fox, 2015). This indicated that the 42 item-instrument used for the study met the unidimensionality trait and was able to measure what it intended to measure (effectiveness of the aids). It also indicated that the data for the 42 items had a very good fit to the Rasch Measurement Model.

Table 2: the determination of unidimensionality of the items

\begin{tabular}{lcc}
\hline & Empirical & Modelled \\
\cline { 2 - 3 } Total raw variance in observations & $62.0(100 \%)$ & $100.0 \%$ \\
Raw variance explained by measures & $21.0(40.3 \%)$ & $40.0 \%$ \\
Unexplained variance in 1st contrast & $6.1(9.9 \%)$ & $14.9 \%$ \\
\hline
\end{tabular}




\subsection{The Second Analysis}

Since this research is qualitative in nature, the hypothesis testing was tested by answering the research questions. For this paper, the research question to be answered was:

$R Q 1:$ How effective is the relief/aid provided?

In order to answer this research question, the data that had gone through the first analysis for the quality control were then used for the second analysis. A wright map was produced to identify the effectiveness of the aids. Figure 1 is the map or also known as logit ruler displaying persons on the left side and items on the right side of the ruler. The persons (flood victims) which were indicated by "\#" were divided into 3 groups by 2 separation lines (as stated in Table 1 - person separation of 2.19).

The group located on the top (labeled as Averaged) were the smallest number, found to be satisfied with most of the items even before the aids were provided to them. They were victims who lived by the road side. Those victims labelled as moderately poor found to be likely satisfied with all items of quality of life. This is because all items (1a-10a) located lower than the location of the victims (indicated by red \#). The poorly satisfied victims found to be satisfied less after the aids provided. Among the items that received low satisfaction were item 1a, 4a, 5a, 6a, 9a and 10a. Items with label 'b' indicated BEFORE the aids, while 'a' indicating AFTER the aids.

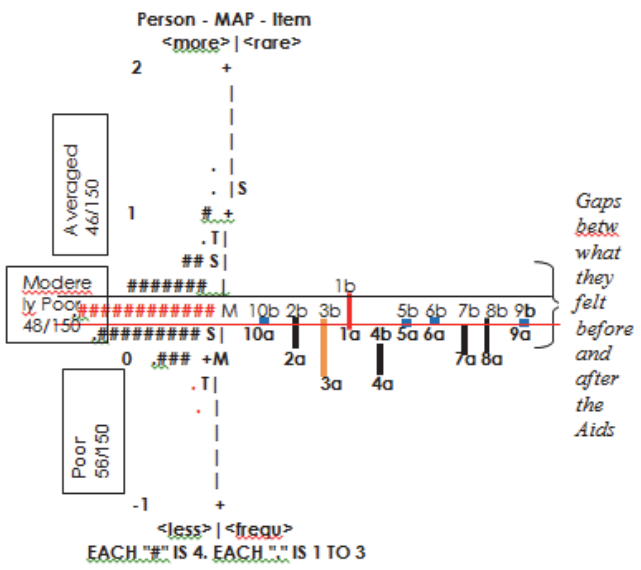

Figure 1: Person item map (a Ruler measuring the effectiveness of aids provided)

The item label is shown in Table 3 below.

Table 3: Item labels

\begin{tabular}{cl}
\hline Item label & Items \\
\hline 1 & Std. of living \\
2 & Food \\
3 & Clothing \\
4 & Health \\
5 & Household income \\
6 & Schooling \\
7 & Community security \\
8 & spirituality \\
9 & Work achievement \\
10 & House condition \\
\hline
\end{tabular}

The line that connected between item $b$ and item a indicating the level of effectiveness of the aids provided. The line coloured in orange representing 0.3 logit gap while the line coloured in black reflecting 0.2 logit gap. The short blue line 
connecting paired item 5, 6, 9 and 10 reflect the little satisfaction the victims had for these items (household income, schooling, work achievement and house condition). This shows that the short term aids provided were not able to improve the victims' satisfaction for household income, schooling, work achievement and house condition.

With reference to Figure 1, the aids (basic necessities, kitchen appliances, temporary house, school kits, and financial aids) were only able to improve the level of satisfactions of the victims in terms for food, clothing, health, community security, and spirituality which were short term in nature.

Overall, the aids were effective as they were able to improve the satisfaction level of the victims especially in terms of their standard of living. This is exhibited by item 1(standard of living). This is because more than half respondents responded positively to $60 \%$ of the items ( 6 items out of 10 items). Many believed that they were more satisfied with the living standard after the aids provided. The gap was marked red as to indicate the highest location of this item against the rest of the items.

Notice that the gap of item 3 (clothing) which marked with orange coloured line is the longest but it falls the second best item to indicate improvement in satisfaction level which reflect effectiveness of the aids. This is because the item was identified by many respondents as satisfactorily even before the aids. And after the aids, they even felt very satisfied. That means the item was not critical enough compared to many other items during the flood. Majority of them felt that they were most satisfied with the clothes that they currently had compared to the clothes they had before the flood.

Other items that showed improvement in the level of satisfaction were item on health care ( item 4), food (item 2), community security (item 7) and peaceful life (item 8). The gap for each paired item was 0.2 logits (the line was coloured black as to denote 0.2 logit gap). This means the likelihood for $95 \%$ respondents to feel secured, peaceful and enough food after the aids. However, $5 \%$ (5 victims indicated by the red dots on the right side of the ruler) felt they were not satisfied with any of the aids provided. These people were those with no income (identified from the ruler).

For item 5 (income), 6 (education), 9 (works) and 10 (house conditions), there were not much improvement as there was not much gap shown on the map. This indicates that majority (67\%) of respondents found not much different before and after the aids. These are the items that need to be given more attention by the Malaysian government in the future. These are the items related to their economic well-being which is permanent in nature. The issue is how to improve the level of satisfaction for these items? Since quality of life depends on human capabilities in terms of health, education, skills and equitable access to opportunities in political, culture and social (Hasanuz Zaman ,1991), government need to provide an aid that is able to generate income within their limited resources and capabilities. Thus, an income generation program that can be materialized in short period but its impact is long term, must be developed as soon as possible by making full use of their available natural resources.

\section{Conclusion}

In conclusion, the aids provided were able to improve the quality of life of the flood victims but the effect was in a short run. Majority of the victims were satisfied mostly with their clothes and their standard of living. This was followed by health, food and social well-being (peaceful life and community security). The effectiveness of the aids were measured by a ruler produced from Rasch Analysis. The ruler measures the effectiveness of the aids provided based on the level of satisfactions the victims had for items related to quality of life. The three different victims were also identified from Rasch Ruler which also indicates the main finding of this study. The victims were the poor, survivor and the average. The effective management of the aids to reach the victims is the primary issue that needs to be discussed further. From the observation, the issues can be categorized into three; such as, the aids successfully delivered to the victims, the aids unsuccessfully delivered to the intended victims and the aids that were not delivered and reached the victims at all.

\section{Acknowledgement}

We are grateful to the Ministry of Higher Education for providing us with Fundamental Research Grant Scheme to the Authors.

\section{References}

Annoni, P. and Biolowolska, D. W. (2012). Quality of life at the sub-national level: an operational example for the Eu, JRC Scientific and Policy Reports, Luxembourg, Publications office of the European Union.

Brown, J. D. and S. L. Damery (2002). Managing flood risk in the UK: towards an integration of social and technical perspectives. Transactions of the Institute for British Geographers, Vol. 27, No. 4, pp. 412-426. 
Cummins, R. A. (2003). Normative life satisfaction: Measurement issues and a homeostatic model. Social Indicators Research.64:2.

Diener, E. (2009) Introduction - Measuring well-being: Collected theory and review works. Social Indicators Research Series, (39)1-6.

Felce, D.,\& Perry, J. (1995).Quality of life: Its definition and measurement.Research in Developmental Disabilities.16(1),51-74.

Hasanuz Zaman S. M. (1991).Economic functions of an Islamic state (The early experience). Karachi: The Islamic Foundation.

Johari,J. \& Ahmad Marzuki,N.(2013), Relating Stress, Anxiety and Depression among Flood Victims' Quality of Life in Malaysia : A Theoretical Perspective, Int. Journal of Social Science and Humanity, Vol. 3 No. 6 Nov 2013.

Reganit, M.P. 2005. Analysis of Community's Coping Mechanisms in Relation to Floods: A Case Study in Naga City, Philippines. International Institute for Geo- Information Science and Earth Observation, Msc Thesis, Enschede, The Netherlands.

Skoufias, E. 2003. Economic Crises and Natural Disasters: Coping Strategies and Policy Implications. World Development Vol. 31, No. 7, pp. 1087-1102.

Tapsell, S., Burton, R., Oakes, S., and Parker, D. J. (2005) The Social Performance of Flood Warning Communications Technologies (No. TR W5C-016): Environment Agency.

Tapsell S., Tunstall S. M., and Wilson T. (2003) Banbury and Kidlington four years after the flood: an examination of the long-term health effects of flooding, Bristol: Environment Agency.

Thrush D, Burningham K and Fielding J, (2005) Exploring flood-related vulnerability:a qualitative study.R\&D Report W5C-018/3. Bristol: Environment Agency.

Twigger-Ross C (2006) Managing the social aspects of flooding: synthesis report, Environment Agency R\&D Technical Report SC040033/SR6.

Werritty A., Houston D., Ball T., Tavendale A. and Black A. (2007) Exploring the Social Impacts of Flood Risk and Flooding in Scotland, Scottish ExecutiveAl-Qardawi, Y. (2004). Poverty and Its Solution in Islam. New Delhi, Adam Publishers \& Distributors. 